that myth has at last caught up with true science. Yet in perhaps his most original chapter he traces the story of Walt Disney's Bambi, the innocent faun, regarded by the hunters' lobby in the United States as its most potent challenge. If this is the popular myth behind conservationism, then the American nature lobby may have more in common with the readers of Aesop than with darwinians.

Like Keith Thomas's Man and the Natural World, which it complements in many ways, this book is an elegant, erudite, stimulating essay on the history of Western ideas about humans and nature; and if it is a story with a moral, then the moral is more appealing than Dart's. But Cart- mill's skill as a writer cannot disguise the fact that this is rather old-fashioned intellectual history. Although he does sketch in the local, temporary ecology of some debates, the overall impression is of an evolutionary tree of hunting myths, or a fossil series, each specimen pregnant with its successor. Seduced by this genealogical fallacy, he makes no use of the anthropologist's cross-cultural casebook. This is a pity, since all these hunting myths are examples of the universal practice of totemism.

Adam Kuper is in the Department of Social Anthropology, Brunel University, Uxbridge, Middlesex UB8 $3 P H$, UK.

\section{How our teachers ought to teach}

\section{Stuart Sutherland}

Schools for Thought: A Science of Learning in the Classroom. By John T. Bruer. MIT Press: 1993. Pp. 324. \$29.95, £26.95.

IN recent years a mindless craze has swept the United States and Britain. Trivial Pursuit has ruined many an American dinner party and the quiz is wrecking the atmosphere of the British pub. Perhaps the popularity of the quiz arises from the rote learning so widely practised in schools throughout the world. I was solemnly taught arithmetic operations borrow one in subtraction and so on without being given any idea why these procedures worked and indeed without any clear understanding that numbers were made up of units, tens, hundreds and so on. Nor were the solutions to algebraic equations or those of logarithms any better explained. One simply had to work it out for oneself.

Schools for Thought suggests ways of overcoming these problems. First, it argues that in executing procedures children often suffer from systematic misconceptions, which make them repeat the same error again and again. It is no use putting a cross against a subtraction wrongly performed; the nature of the error should be identified and the correct procedure explained. Children may consistently forget to borrow one, they may fail to carry a borrow across two places and more bizarrely they may always subtract within a column the smaller number even if it belongs to the subtrahend. Such incorrect procedures are hard for the teacher to detect as a single error may be random rather than an example of the use of a wrong rule: they can, however, readily be detected by computer if the child's efforts are fed directly to it.

J. T. Bruer argues that new concepts will be most readily grasped if they are linked to what the pupil already knows. Most children starting school can already count a group of objects by touching each in turn and uttering the next number. To facilitate their grasp of arithmetical procedures, they can be presented with differently sized blocks representing units, tens and hundreds. The blocks correspond to the figures in a sum, which the children do in the normal way while simultaneously manipulating the blocks: this technique, which has been in use for some time, bears more than a slight resemblance to the old-fashioned abacus.

Bruer maintains that students learn best through disputation with one another and the teacher. One outstanding American teacher of physics found that his pupils, who had done excellently in examinations, could not transfer their formal learning to "the physics of everyday situations, and they showed little understanding of basic physical concepts such as force, motion and gravity". Equations can be learnt by rote, but that does not constitute understanding. To overcome this, he probed his students to discover their naive opinions on physical laws. Opinions varied - some might think that an object in a vacuum will be weightless, whereas others believe it will have weight. The disagreement is resolved by demonstrating experimentally that bodies do have weight even in a vacuum. Again, most people bring to physics such false beliefs as that only a moving object can impart a force and few understand the effects of a force applied to a moving object, but pupils can apparently readily grasp the correct laws by experimenting with a computer display programmed to simulate Newton's laws. They learn by subjecting a moving sphere to different forces and observing the results.

On the use of new methods of teaching reading and writing, Bruer is less persuasive. He suggests that vocabulary should be taught by exposing students to groups of words in the same category, for example, ten words describing people such as 'accomplice', 'virtuoso' and 'novice'. After the words are learned the teacher gives a clue to one of them - for instance, 'crook'. The students shout 'accomplice', and are asked to explain the connection between the two words. The object is to build up schemata that incorporate sets of concepts and their interrelationships. Sensibly, Bruer points out that many elementary reading texts require a background of concepts that the students simply do not have. It is no use giving them a passage on the American Revolution that refers to 'the 13 colonies' if they have no idea what that means. This problem can be solved either by changing the texts or by giving children more background information before they read them.

Bruer claims that these innovations in teaching, most of which were inaugurated and tested by psychologists, stem from advances in cognitive psychology. Perhaps they were triggered by that discipline, but they come perilously close to ingenious common sense. Nevertheless, they all appear to work and when compared with conventional teaching they raise students' ranks in tests by anything between 20 and 40 percentile points.

There are, however, problems. All the methods are time consuming, both for the teacher and for the pupil. Using the techniques for teaching physics already described, students took more than a week to learn Newton's laws instead of the normal day or two. Perhaps conventional methods would do just as well if as much time were devoted to a given topic. It is, moreover, well known that introducing any novelty into an institution produces good results - for a time: both the teachers and the pupils are likely to be more enthusiastic and better motivated.

Nevertheless, Bruer is on the side of the angels, in that he believes students should be taught to understand and to think, but the conservatism of school teachers and the ignorance of governments are likely to die hard. Answering multiple-choice questions requires neither originality nor thought, yet many of the new tests in British schools will be based on them. Most American universities use such tests as a method of assessment and to their shame some British universities have now introduced them. Writing an essay or solving a problem requires thought and some originality, but few now are interested in those capacities. The current ethos is that the teacher is there to cram pupils with facts, if only to impress examination boards and quiz masters.

Stuart Sutherland is in the Laboratory of Experimental Psychology, University of Sussex, Brighton BN1 9QG, UK. 